\title{
In Defense of the Populist Lecture
}

Mark Lawrence Schrad, Villanova University

\section{ABSTRACT Information and communication technology (ICT) programs like Microsoft} PowerPoint and Apple Keynote have become the norm for large university lecture classes, but their record in terms of student engagement and active learning is mixed at best. Here, the author presents the merits of a "populist" lecture style that takes full advantage of the variety of features available from the latest generation of ICT programs. Based on visual variety, audio and visual sound bites, and the incorporation of humor and pop-cultural references, this populist approach not only facilitates greater student attention and engagement with the class materials, but also offers unmatched opportunities for extending student learning beyond the confines of the large lecture hall.

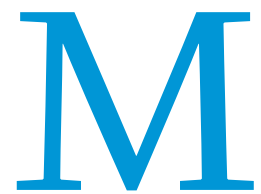
y first large university lecture experience was unforgettable: a lowly TA stand-in for an introductory class of 400-on Halloween, no less. In that cavernous lecture hall, I remember witnessing the usual diversity of student behavior: some frantically duplicating every word from my PowerPoint slides, some staring blankly into space, and others on the brink of dozing off as I nervously delivered a decidedly uninspiring overview of post-Soviet politics. Nothing about the scenario was unusual, until about ten minutes into the lecture, when a group of eight students stormed the classroom from the back of the hall, all dressed for Halloween as bananas, being chased by a student in a gorilla costume! They whooped and hollered as they came down the aisles, performed a staged slapstick routine for a few seconds, and then dashed out the emergency exit, stage right. Needless to say, it was quite a shock to everyone in the hall, myself included. Once it became clear that the incident was an innocent Halloween prank, we all had our laughs and eventually got back down to business. That is, until ten minutes later, when the same group of students again stormed the auditorium, this time dressed as bowling pins being chased by a giant bowling ball. And then again, fifteen minutes after that, as a group of Spaniards from Pamplona, complete with red kerchiefs, running from the bulls-or cows, in this instance (it was Wisconsin, after all). What could I do? New instructor orientations rarely cover what to do in the event of a gorilla invasion. All I could think to do was to laugh along and say, "Well, I can't compete with that!"

The students' end-of-semester evaluations confirmed a hunch that I had-surprisingly, the students claimed to have both enjoyed and learned quite a lot from that particular lecture. Seemingly, the dramatic interruption not only refocused the students' attention on the materials, but also, the humorous intrusion was

Mark Lawrence Schrad is an assistant professor of political science at Villanova University. His most recent work includes The Political Power of Bad Ideas: Networks, Institutions, and the Global Prohibition Wave. He can be reached at mark.schrad@villanova.edu. strangely disarming, making me more at ease with the lecture and leading the students to respond in kind.

I have since transformed the lessons learned from the "gorilla humor" of that day into the "guerrilla humor"-quick and unexpected injections of humorous content to refocus student attention (Hellman 2007, 37)-that can be part of a comprehensive teaching package that holds student interest and creates a classroom atmosphere conducive to learning, especially in large lecture courses. The effective integration of a number of pedagogical techniques, which include an ever-changing variety of materials, approaches, humor, visuals, music, pop culture, and video clips, all facilitate greater student engagement and active learning that can overcome the traditional "Death by PowerPoint" that has become the bane of the large lecture class (quoted in Clark 2008, 40). It is this integration of such techniques that I have in mind when I describe a "populist" approach at the lectern.

\section{PATHOLOGIES AND POTENTIAL OF} POWERPOINT PEDAGOGY

There is a longstanding debate in university pedagogy over the effectiveness of information and communication technology (ICT), including Microsoft PowerPoint and Apple Keynote programs, which have become the norm for scholarly presentations and have subsequently been derided as potential impediments to student learning, rather than facilitators. Early and enduring criticisms of ICT presentations have focused on how the technology's limitations (such as resolution and space restrictions that facilitate the replacement of complex ideas with oversimplified outlines and bullet points) promote a dumbing down of the classroom environment, as substance is sacrificed to technique, aesthetics, and style (Apple 1991; Tufte 2003; Turkle 2004). Others suggest that the traditional line-by-line, bullet-point PowerPoint templates reflect standards of adult professional learning that are ill-suited to a younger college-age audience that generally lacks a broader contextual knowledge (see, e.g., McNickle 2003). ${ }^{1}$ 
Small classes that facilitate face-to-face communication are preferable for achieving greater depth of student attention, comprehension, and active learning, yet they are impractical for many university courses, especially introductory-level courses that only seem to grow larger in size every year. Accordingly, the activelearning techniques that one might employ in a class of 10 or 12 become impossible in courses of 40 , much less 400 . For better or worse, the PowerPoint lecture has become an unavoidable reality for most university instructors. But must the associated pitfalls of PowerPoint necessarily follow? Is there a way to avoid the audience boredom and disengagement reflective of the passive learning that traditionally accompanies large lecture presentations in which students become "spectators rather than participants" (Reinhardt 1999, 49)?

When compared to earlier technologies-overhead projections, slideshows, blackboards, and unaided lectures-ICT programs have a decided advantage in terms of aiding note-taking and study revision (Gilroy 1998; Frey and Birnbaum 2002). Yet, by themselves, ICT presentations do not necessarily equate to the greater student interest, attention, and engagement that are crucial to maintaining active student learning and higher order thinking. In an effort to understand what does and does not work in terms of maintaining student attention, Clark (2008) underscores the importance of a variety of visual stimuli in capturing and maintaining student attention and interest. Rather than presenting an unending sequence of black-and-white Helvetica bullet points, Clark's survey findings suggest that the incorporation of relevant pictures, graphs, maps, and landscapes-as well as a variety of projection backgrounds-focuses student attention. Such findings have been substantiated in political science courses, in which the use of visual imagery has been shown to enhance student engagement and interest in political topics (Ulbig 2009). Clark's study concludes that the technological capacity of ICT programs are best fused with the creative impulses of the instructor: "PowerPoint offers a host of opportunities to present slides in a variety of ways, and it is important that variety be exploited if interest in the lecture is to be maintained" $(2008,43)$.

The pedagogical potential of ICT programs has grown in step with advances in technology. While early versions of PowerPoint offered a limited repertoire of fonts and backgrounds, today, built-in templates and Web-based add-ons offer a near-infinite range of presentation styles, while slide animations and the ability to incorporate audio and video files into lecture presentations present a tremendous opportunity to engage students and stimulate deeper understanding of class concepts.

\section{TECHNICAL LOGISTICS}

A populist approach to large lecture classes exploits the full potential of current ICT technology to maintain student interest in what may admittedly be (at times) distant and uninteresting academic topics. This approach has the potential not only to maintain student interest in the lecture hall, but also to facilitate student learning outside the classroom by relating often-esoteric course concepts to cultural reference points in which the student may already be interested, or by making the student aware of other potential opportunities outside the classroom. What follows is a brief description of my approach to constructing a populist multimedia ICT presentation.

Among available ICT programs, Apple Keynote presents the greatest variety of slide templates, transition and animation schemes, and ease for incorporating audio and video materials. Visual/photographic (.jpg), audio (.mp3), and even video (.mov or .mpg) files can easily be dragged and dropped onto a Keynote lecture slide; edited for length, size, and appearance; and animated for transitions in a matter of seconds.

Video clips can similarly be inserted into a PowerPoint presentation, although there are problems of file compatibility: a QuickTime (.mov) video file is not compatible with PowerPoint on a $\mathrm{PC}^{2}$ and must be converted to either an MPEG (.mpg or .mpeg) or Windows Media (.wmv) file before it can be added to a PowerPoint slide. Then, instead of simply dragging and dropping (or cutting and pasting) the video file into the slide as with Keynote, you must select the proper destination slide, choose Insert $\rightarrow$ Movies and Sounds $\rightarrow$ Movie From File, and locate the desired clip wherever it is stored on the computer. Establishing this link is crucial, because in PowerPoint (unlike Keynote), the video clip does not become part of the ICT presentation; rather, it remains only as a link. Thus, if you attempt to move your PowerPoint presentation to another computer without also transferring all of the video files linked to it, the videos will not work. Such additional complications make PowerPoint more cumbersome in practice compared to Keynote.

In some cases, it is necessary to first create media files, for which a screen capture program such as Ambrosia Software's Snapz Pro X is particularly handy. Snapz Pro allows you to record anything that you can see or hear on your computer screen with surprising ease. You can snap a picture of anything on your screen-graphs, charts, pictures-from the Internet or any program that your computer can run and save it instantly as a .jpg file. SnapzPro can also record any audio track that can play over the computer's speakers as an .mov QuickTime file. The most useful feature of this program, however, is its ability to combine audio and visual elements, allowing you to capture any section of video that can be displayed on your computer screen, be it from documentary, Hollywood, or Bollywood DVDs playing through a media player, streamed videos from online news sources, or clips from YouTube.

There is a tradeoff between file size and quality in making .mov QuickTime files. The larger the area (in pixels) that you record and the longer the video clip, the larger your file will be. An additional consideration is the frame rate at which the program records the video content: at 12 frames per second, the recording rate allows for a reasonably fluid video product while maintaining a manageable file size. Making clips of shorter length (1-2 minutes) and smaller area (e.g., 3 in $\times 4$ in)-which can later be blown up with only a slight loss of resolution-leads to videos of manageable file size. While future technological advances will presumably render file-size considerations unimportant, at the present time, the size and number of files is a serious practical concern: creating a library of movie files in such a manner can quickly clutter even the largest hard drive, while adding these files into presentations also increases the size of the ICT files, further reducing hard drive space.

QuickTime video files can easily be renamed to describe the contents of the movie clip before being filed in an appropriate folder. This approach has an added benefit when creating ICT presentations: a keyword or spotlight search for the topic of the lecture-for example, "democracy," "perestroika," or "war"-will quickly result in a list of every file in your library that you have made on that topic. This organizational approach not only 
accelerates the process of lecture writing, but it can also enrich the process by reminding you of files or potential tie-ins that may otherwise be forgotten.

In cyberspace, it is common practice to embed Internet links or videos available on the Web into blogs or other fora. While similar linking of visual, audio, or even video material is possible in ICT programs, Internet links are unreliable, as URLs frequently change or disappear altogether. Unlike a library of hard copies of video materials, embedded Internet links make the instructor dependent on an uninterrupted Internet connection for the duration of the presentation. Using a screen-capture program like Snapz Pro to create hard copies of visual, audio, and movie files allows you to readily incorporate a wide variety of materials into ICT presentations without the risk that the files will become inaccessible at the moment they are most needed.

Time is of the essence in large classes, and while instructors have long incorporated audio and video elements-from musical interludes to VHS documentaries-into their lectures, embedding files directly into an ICT presentation has the added benefit the ICT presentation. The instructor could play the clips backto-back in one five-minute segment or split them up to hammer home the relevance of the clips in between. In either scenario, not only does the instructor waste less time on the set-up and inclusion of irrelevant materials, but ICT integration also allows the lecture to flow seamlessly between the concepts presented by the instructor orally and the supporting evidence presented in the video clip. Indeed, numerous studies have demonstrated that such a union of visual and verbal information boosts recall and facilitates mental connections, stimulating student learning (Hallett and Faria 2006; Nowaczyk, Santos, and Patton 1998; Chanlin 1997; Chanlin 1998).

\section{VIDEO KILLED THE POWERPOINT STAR}

As political scientists, we are fortunate that the content of most of our courses-social issues of power and competition, war and peace, trust and betrayal-make great fodder for television and movies, both comedies and dramas. Previous volumes of PS have promoted the pedagogical potential of pop culture from music (Soper

\section{While students can learn a tremendous deal about the power dynamics of the Cold War,}

the security dilemma, and mutually assured destruction (not to mention the comedic genius of Peter Sellers) from a viewing of Dr. Strangelove, it is not necessary to watch all 93 minutes of that film to convey all of these points. Presenting a few video clips of the most appropriate and humorous segments of this macabre comedy to an introductory course on international relations not only allows the instructor to underscore the relevant conceptual elements and simultaneously invigorate the classroom atmosphere, but it also saves one or perhaps two lectures that would otherwise have been occupied were the class to watch the movie in its entirety.

of allowing more efficient use of class time. In a typical IT-enabled lecture hall, if an instructor wants to break up a conventional PowerPoint lecture with a video clip, she often needs to switch from the presentation to a separate DVD or VHS cassette player and queue up the appropriate scene. This process can take a great deal of time, especially if the instructor is unfamiliar with the particular IT setup or if the VHS tape has not been rewound since its last use. Bringing the lecture to a screeching halt not only wastes valuable class time, but it also breaks the flow of the lecture, allowing the students an opportunity to become disengaged or forget the relevance of the clip to the material (McKeachie and Svinicki 2006, 68). Moreover, traditional films are often inefficient in conveying the point that the instructor is trying to make. For example, an instructor may have a 10-minute clip from an excellent documentary on a particular class topic. In such circumstances, the most relevant segments usually appear at the beginning and end of the clip. (Otherwise, why not start the clip later or end it sooner?) Assume that, of the 10-minute clip, there is a very good three-minute spot at the beginning and another two-minute spot at the end, with five minutes of meandering, off-topic cinematography in between. A more effective alternative to running the entire 10 minutes would be to use a screen-capture program to make a clip of the first three minutes and the final two minutes, and to then drop them directly into
2010) and literature (Lieberfeld 2007) to television (Beavers 2002) and film (Lindley 2001); elsewhere, others have uncovered significant influences on learning and engagement of student viewers of late-night political satire shows, such as the Daily Show (Baumgartner and Morris 2006; Beavers 2009). For all of this potential, however, even pop culture tie-ins suffer the same problems of documentary presentations in the classroom-they emphasize story development and cinematography at the expense of relevant concepts. While students can learn a tremendous deal about the power dynamics of the Cold War, the security dilemma, and mutually assured destruction (not to mention the comedic genius of Peter Sellers) from a viewing of Dr. Strangelove, it is not necessary to watch all 93 minutes of that film to convey all of these points. Presenting a few video clips of the most appropriate and humorous segments of this macabre comedy to an introductory course on international relations not only allows the instructor to underscore the relevant conceptual elements and simultaneously invigorate the classroom atmosphere, but it also saves one or perhaps two lectures that would otherwise have been occupied were the class to watch the movie in its entirety. A good populist lecture balances the benefits of the occasional, brief diversion with the need to make the most of classroom time. As with "gorilla/ guerrilla humor," it is key to make the point, perhaps have a laugh, and then move on. 
From campaign advertising to the evening news, political scientists have long appreciated that we live in a world of soundbites. Our information today arrives prepackaged in discrete segments. The current generation of undergraduate students who populate our large lecture halls have grown up constantly bombarded by video soundbites. They are a generation of extensive information consumers-"channel surfers" who scatter their attention rather than focus it (Cowen 2002, 91). This tendency may be one reason why it is often difficult for students to maintain their interest in a single topic over the duration of a 50 - or 80 -minute lecture (see, also, Wilson and Korn 2007).

Instead of struggling against these inherent attributes of the audience, a better approach is to recognize the opportunities they present for enhancing learning. Many of the issues and concepts in our discipline find parallels and often humorous tie-ins to the realm of pop culture, and one need not spend more than a few moments to make such a point. Making those linkages explicit not only helps to clarify class concepts as they are being presented, but also allows for ease of recall at a later date, which both eases the process of studying for exams and paves the way for students to expand their active learning beyond the lecture hall (Robinson and Kakela 2006). Building on the previous example, students interested in international relations or Cold War history might even rent Dr. Strangelove (or another movie discussed in class) and watch it-perhaps in a social setting with their roommates or fraternity brothers or sorority sisters-in its entirety on their own time. Or, if they happen to stumble across the movie in progress on cable $\mathrm{TV}$, they might be more prone to remembering that, "Oh yeah, we watched a part of this movie in Professor X's class. She said that it was all about concepts Y and Z." The ability to plant such "learning grenades" in the minds of students-that later explode to reinforce learning in an outside social setting-is one of the inherent benefits of a populist approach to lecturing.

One can find literally hundreds, if not thousands, of potential pop culture tie-ins for virtually any class in political science. Some classics include Ben Stein's deadpan explanation of the HawleySmoot Tariff Act to a sea of blank expressions in Ferris Bueller's Day Off, the debate between the anarcho-syndicalist peasant and King Arthur on the shortcomings of dictatorship in Monty Python and the Holy Grail, the rants of Howard Beale (Peter Finch) in Network to describe the dramatic imperative and bias in corporate media, and All Quiet on the Western Front on the reasons for war, among others. The underlying themes of entire movies often revolve around the same topics we discuss in our large lectures: Saving Private Ryan illustrates the tensions between just-war principles and rational self-interest in modern warfare, Lethal Weapon 2 is built around the issue of diplomatic immunity, Charlie Chaplin's Great Dictator examines nationalism and totalitarianism, Hotel $R w a n d a$ lays bare the horrors and dynamics of mass genocide, and even Disney-Pixar's Wall-E can be viewed as an illustration of the basic problems of delegation in principal-agent theory.

Take, for instance, the following exchange between two escaped prisoners, Pete (John Turturro) and Ulysses Everett McGill (George Clooney), looking for direction and leadership while on the lam in the movie $O$ Brother, Where Art Thou:

Pete: Wait a minute. Who elected you leader of this outfit?

Ulysses: Well, Pete, I figured it should be the one with the capacity for abstract thought.
I use this clip in my introduction to political science class when discussing Plato's deep-seated distrust of "the multitude." Based on similar assumptions, Plato argues that only those people who can see true forms-the philosophers, those with the capacity for abstract thought-should rule. Of course, it also helps that $O$ Brother is a screen adaptation of Homer's Odyssey, reinforcing a tie-in to ancient Greece. This clip is all of eight seconds long. In that time, the clip (1) illustrates a concrete application of a vital class concept, (2) uses characters both real (George Clooney, John Turturro) and fictional (Pete, Ulysses) to whom the students can relate, (3) establishes a link to facilitate subsequent learning in social settings beyond the classroom, (4) breaks up the monotony of a lecture, and (5) uses humor to refocus student attention on class topics. I have honestly yet to meet a university instructor so gifted with oratorical skill that he or she can claim to achieve so much in so limited a space.

\section{SURVEY DATA}

To discern whether the use of advanced audio/visual capabilities of ICT technologies combined with the injection of elements of humor, current events, and pop culture references could enrich, rather than stifle, the content of class materials, I submitted midsemester questionnaires to students in my undergraduate political science classes at the University of Illinois at UrbanaChampaign over the period of 2008 to 2010. In addition to allowing room for open-ended survey results, the questionnaire included the Likert-scale question, "Which one of the following statements about the use of video clips in the lecture format most accurately describes your position?" (see table 1).

The quantitative scores, as shown in table 1 , are quite striking. Of the 1,271 total respondents, only 17 had a negative impression of the presentations, while an additional 29 were indifferent. In contrast, the remaining 1,225 respondents (96\%) responded positively to the videos, with $284(22 \%)$ indicating mild amusement and the overwhelming majority-941 (74\%) -stating that the incorporation of video clips into the lecture format was useful for illustrating course concepts and maintaining student interest.

These indicators definitively suggest that the incorporation of a wide variety of audio and visual stimuli into the lecture environment helps maintain student attention. To gain greater leverage on why students appreciate this variety of populist video clips, we may turn to the content of anonymous mid-semester and end-ofsemester course evaluations, many of which suggest that incorporating audio and visual elements into the lecture bolsters student attention and aids recall:

- "Lectures and slides in any class are monotonous after awhile. Video clips are a fun, entertaining addition to the presentation which make it easier to concentrate and also make a subject/concept more relatable. We appreciate the extra effort!" (PS395)

- "I like the powerpoints-keep you engaged. Good idea not to post them [online], makes people come and makes people take notes." (PS282)

- "I really like the use of video clips because it keeps my attention and adds humor. Plus they help me focus on the points the clips are related to." (PS282)

- "I believe my instructor always adds more to the material, like current events, more detailed explanations, and TV/movie clips that enhance my understanding. Lectures are always 


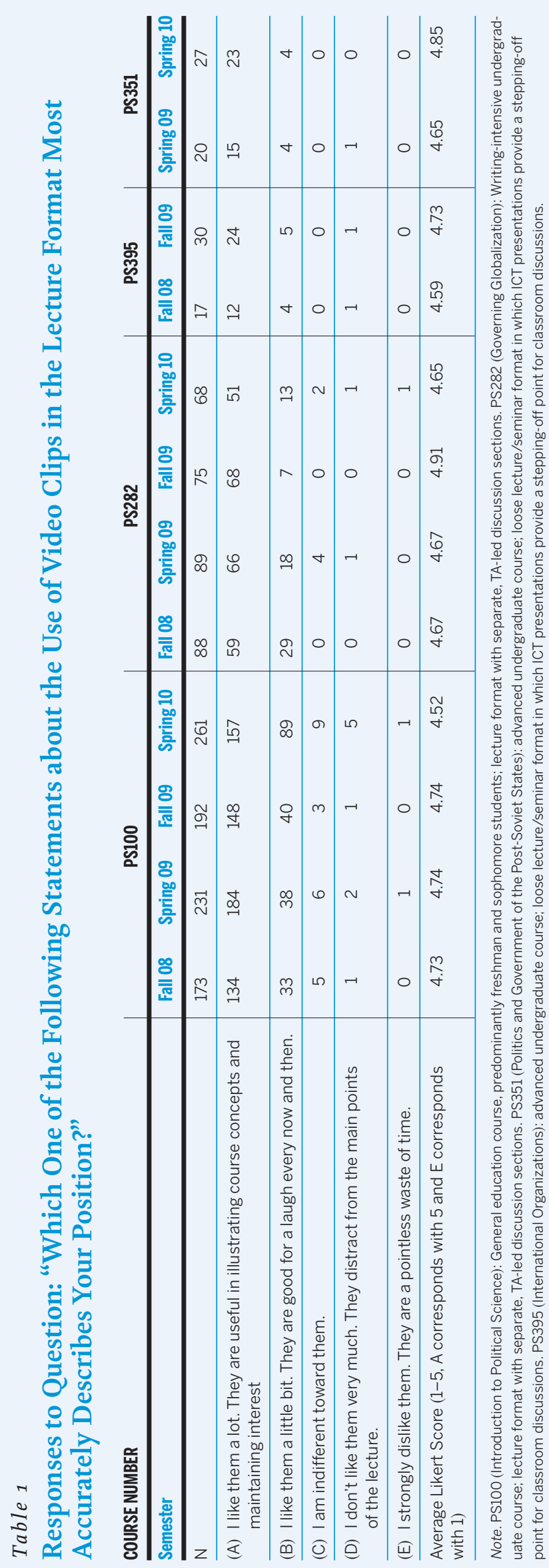

entertaining and thought-provoking and relate to what's going on." (PS10o)

- "Instructor understands how students work and is very responsive to them. I like [the videos] a lot. The videos keep interest up, and they are well picked and come from a diverse catalog. Having Rocky and Bullwinkle ${ }^{3}$ and videos that are more obscure is the most effective and interesting." (PS395)

Particularly worthy of mention are the responses that suggest a correlation between a populist lecture style and increased lecture attendance, especially for early morning classes:

- "Keep the videos. At 8:30am especially, and with material that could be dry, the videos and the overall presentation make the class very interesting and worth coming to." (PS282)

- "Presentations were excellent! I honestly loved coming to this class and would come rather than sleep in because of how interesting he made the material." (PS10o)

- "I felt the professor of this course was very passionate about what he was teaching and I appreciated his enthusiasm at 8:30 in the morning! I felt he could explain complex concepts in a very easy way that everyone could understand. While I enjoyed the video clips, I felt some of them were put in and didn't really relate, but as long as we have time and it doesn't take away from talking about something, then why not? It is nice to have something to laugh about when you have to get here at 8:30am. I think the prof. did a good job integrating them and they never took too much time $\mathrm{b} / \mathrm{c}$ he was always prepared." (PS282)

\section{IMPLICATIONS}

Unsurprisingly, both the questionnaire data and the subjective assessments indicate that students overwhelmingly respond positively to a populist lecture style-which is why it is so dubbed in the first place. They find the video clips and pop culture references useful in illustrating course concepts, maintaining interest, and breaking the monotony of a conventional, large-size university lecture. The subjective assessments also suggest that the stimulation of interest might result in greater attendance in lectures, even when they are scheduled early in the morning.

These results generally corroborate the findings of Clark (2008), which suggest that ICT presentations best hold student attention when they offer a variety of visual stimuli, as student interest is often linked to anticipation, visual variety, and change. While the approach that I outline here presents great potential for heightening student engagement and achievement, we must also temper our expectations about the potential of new technologies with the realization that ICT programs are tools to facilitate understanding. Indeed, my findings echo Clark's conclusion that "students did not see PowerPoint in isolation but rather as part of a pedagogical package, including the interest the topic held for them, the personality and delivery style of the lecturer, and even when the lecture was delivered at the end of the day. The teacher's role is crucial" (Clark 2008, 42). The ability of an instructor to create a stimulating classroom environment is certainly a function of his or her passion, enthusiasm, and creativity (Baum 2002), and the variety of ICT programs only provides additional outlets for that creative energy. 
While generally eliciting a positive student response, this approach also has many practical downsides. First is the issue of sunk costs. At this time, multiple gigabyte ICT presentations stretch the technological capacities of all but the most recent computer systems. For some instructors, this requirement might necessitate purchasing a new computer with more advanced technological capabilities, as well as a larger external hard drive to warehouse a library of video files. Second is the issue of time constraints. Creating a large clip library can take a great deal of time, since one must locate the particular documentaries, online videos, and movies; queue them up to the right size; and record and name them. For some, the time gained in conducting a more organized, efficient classroom lecture may not be worth the outlay of time spent in prelecture preparations.

The third downside is the potential property rights issue. In the United States and elsewhere, the use of copyrighted materials without permission of the copyright holders falls within the definition of "fair use," provided that (1) the materials are used for educational rather than commercial purposes, (2) the amount of material used is a limited percentage of the whole work, and (3) the effect of the materials' usage does not diminish or infringe upon the potential market for the original copyright. In all of these aspects, limited use of audio and video clips should be considered legal and (as described previously) might even further sales or rentals of the original copyrighted work-a free advertisement, if you will. Of course, to be on the safe side, it would be wise to generally refrain from publishing such lectures online without proper attribution of the original creators, which might transform such creations into commercial products.

Fourth, there is the problem of novelty. When the first ICT programs came into widespread use a decade ago, many were initially mesmerized by the new technology-but as PowerPoint and Keynote have become a staple of presentations in both business and academia, the novelty has worn off, prompting questions and pedagogical studies of the technology's effectiveness. The populist lecture is effective in part because it is unusual. Certainly, there is no guarantee that such techniques will be equally as effective if every professor uses them in every class. Novelty wears off, prompting the question of what comes next?

Finally, there is the issue of active learning. Active engagement and intellectual dialogue with course content are the goals of higher education, whether they occur in an intimate discussion section or a large lecture hall. This cultivation of critical thinking is the hallmark of the American system of higher education. Students need to become active participants in the classroom rather than passive consumers of information. Does the populist lecture contribute to the cultivation of higher order thinking amongst the students? Here, the record is unclear. Certainly, there is the potential for students to become passive observers of the populist lecture, especially when this approach is compared to the alternative of a small, discussion-oriented classroom environment. On the other hand, students' appreciation of the instructor's extra effort to make a more stimulating, and even entertaining, learner-centered classroom environment generally correlates with increased student motivation and learning (Straits 2007). In either case, because the modern system of higher education seems to dictate ever-greater class sizes at the expense of small, intensive classes, the populist approach at least presents a more stimulating and engaging learning environment than the conventional alternative.

\section{IN DEFENSE OF THE POPULIST LECTURE}

When Marshall McLuhan wrote, "When new technologies impose themselves on societies long habituated to older technologies, anxieties of all kinds result" $(1985,58)$, he might as well have been discussing traditional reactions to a populist lecture style that makes full use of the latest generation of ICT technologies. To be sure, such an approach can produce tensions with instructors who are hesitant to engage with pop culture and the world outside academia. These anxieties may take the form of the (false) assumption that any injection of "style" into a lecture necessarily comes at the expense of "substance"; arguments in favor of forcing students to adjust their styles of learning rather than requiring the instructor to adjust his or her style of teaching; instructors' desire not to "pander" to the interests or purportedly shorter attention spans of students; or scoffing dismissals of student self-evaluations that claim that students do not properly understand what effective teaching is, and therefore anything that students actually enjoy-anything that holds their attention or keeps them engaged-is necessarily bad. Throughout this article, I have sought to dispel such stale arguments. Indeed, even those instructors who prefer to teach a particular intellectual paradigm without "stooping" to popular culture can, for instance, integrate documentary video clips into an ICT lecture to save precious class time and reinforce course concepts.

On the other hand, we should avoid an unquestioning embrace of technology and gadgetry, as many pedagogical innovations have the potential to foster student disengagement and passivity rather than encourage involvement and higher order thinking skills. For instance, using technology to expand the availability of lecture materials outside the classroom environment, either by broadcasting lectures as podcasts (Roberts 2008), posting lecture notes to course Web sites or Blackboard programs, or distributing notes as in-class handouts (Clark 2008; Hove and Corcoran 2008; Gier and Kreiner 2009) can often discourage classroom attendance and engagement with course content. ${ }^{4}$

Good teaching in a university setting ultimately depends much more on the instructor than on any technology (Hardin 2007), yet good instructors should be aware of the ever-expanding variety of instructional tools that can facilitate student learning. My experience suggests that an intrusion of gorillas, bowling balls, and bull-runners does wonders for increasing student attentiveness and engagement in a large lecture class-but when such options are in short supply, modern ICT programs offer a wide variety of useful alternatives. Incorporating audio and video elements, current events, and even humor and pop culture references into a lecture makes for a more stimulating, engaging, and enjoyable classroom environment for both the students and the lecturer. While small, intimate discussion seminars may still be the gold standard when it comes to facilitating active learning and higher order thinking skills, the elements of the populist lecture that I present here go far in making for a more effective and efficient use of time in large lecture classes.

Ultimately, in a university lecture environment, "learning is not what is poured from the pitcher, but what lands in the glass" (Gray and Madson 2007, 85). Anything that encourages greater attendance leads to the presence of more glasses, and an increased ability to connect with students through a populist lecture means that those glasses will be fuller than they would have otherwise been. I 


\section{NOTES}

In addition to the two the two anonymous reviewers, I would like to thank the department of political science at the University of Illinois, where many of the classroom tech niques in this article were developed. Special gratitude goes to the following graduate assistants: Sheena Arackal, Alexandru Balas, Adam Bilinski, Amanda Cronkhite, Bryce Dietrich, Katherine Graham, Andrea Kent, Dongsuk Kim, Shyam Kulkarni, Shweta Moorthy, Gennady Rudkevich, Jamie Scalera, Matthew Spears, Konstantinos Travlos, and Nini Zhang.

1. I am indebted to an anonymous reviewer for highlighting this point.

2. However, PowerPoint programs that run on a Mac rather than a PC can support.mov files (http://www.indezine.com/products/powerpoint/ ppquicktime.html).

3. The Rocky and Bullwinkle reference in question consisted of a four-second video clip of a fictional encounter between Mr. Peabody and Sherman with Spanish conquistador Francisco Pizarro, who pleaded with the Incans for kind treatment, because, in his words, "I am only an observer from the UN." That such an arcane four-second clip would be remembered and referenced weeks later speaks to the potential of incorporating such pop culture references as illustrations of class concepts-in this case, the impartiality of United Nations officials.

4. Indeed, the incorporation of multimedia into ICT presentations expands the available list of reasons for not posting lectures online to include technological and legal considerations. An instructor reluctant to post his or her lectures online could reasonably cite both the technological difficulties of posting, say, a two-gigabyte ICT file to the Internet and the potential legal liability for publishing under his or her own name media that includes previously copyrighted materials as excuses for not doing so.

\section{REFERENCES}

Apple, Michael W. 1991. "The New Technology: Is It Part of the Solution of Part of the Problem in Education?" Computers in Schools 8: 75.

Baum, Lawrence. 2002. "Enthusiasm in Teaching." PS: Political Science \& Politics 35 (1): 87-90.

Baumgartner, Jody, and Jonathan S. Morris. 2006. "The Daily Show Effect: Candidate Evaluations, Efficacy and American Youth." American Politics Research 34 (3): $341-47$.

Beavers, Staci. 2002. "The West Wing as a Pedagogical Tool." PS: Political Science $\mathcal{E}$ Politics 35 (2): 213-16.

. 2009. "Getting Political Science in on the Joke: Using TV's The Daily Show to Teach Introductory U.S. Politics." Paper presented at the 67th National Conference of the Midwest Political Science Association, April 2-5, Chicago, IL.

Chanlin, Lih-Juan. 1997. "The Effects of Verbal Elaboration and Visual Elaboration on Student Learning." International Journal of Instructional Media 24 (4): 333-39.

_. 1998. "Animation to Teach Students of Different Knowledge Levels." Journal of Instructional Psychology 25 (3): 166-75.

Clark, Jennifer. 2008. "Powerpoint and Pedagogy: Maintaining Student Interest in University Lectures." College Teaching 56 (1): 39-44.

Cowen, Tyler. 2002. Creative Destruction: How Globalization Is Changing the World's Cultures. Princeton, NJ: Princeton University Press.

Frey, Barbara A., and David J. Birnbaum. 2002. "Learners' Perceptions on the Value of PowerPoint in Lectures." East Lansing, MI: National Center for Research on Teacher Learning. ERIC Document Reproduction Service No. ED467192.
Gier, Vicki S., and David S. Kreiner. 2009. "Incorporating Active Learning With PowerPoint-Based Lectures Using Content-Based Questions.” Teaching of Psychology 36 (2): 134-39.

Gilroy, Marilyn 1998. "Using Technology to Revitalize the Lecture: A Model for the Future." East Lansing, MI: National Center for Research on Teacher Learning. ERIC Document Reproduction Service No. ED437123.

Gray, Tara, and Laura Madson. 2007. "Ten Easy Ways to Engage Your Students." College Teaching 55 (4): 83-87.

Hallett, Terry L., and Geraldine Faria. 2006. "Teaching with Multimedia: Do Bells and Whistles Help Students Learn?" Journal of Technology in Human Services 24 (2): $167-79$.

Hardin, Erin E. 2007. "Presentation Software in the College Classroom: Don't Forget the Instructor." Teaching of Psychology 34 (1): 53-57.

Hellman, Stuart V. 2007. "Humor in the Classroom: Stu's Seven Simple Steps to Success." College Teaching 55 (1): 37-39.

Hove, M. Christina, and Kevin J. Corcoran. 2008. "If You Post It, Will They Come? Lecturing Availability in Introductory Psychology.” Teaching of Psychology 35 (2): 91-95.

Lieberfeld, Daniel. 2007. “Teaching about War through Film and Literature." PS: Political Science \& Politics 40 (3): 571-74.

Lindley, Dan. 2001. "What I Learned since I Stopped Worrying and Studied the Movie: A Teaching Guide to Stanley Kubrick's Dr. Strangelove." PS: Political Science and Politics 34 (3): 663-67.

McKeachie, Wilbert J., and Marilla Svinicki. 2006. McKeachie's Teaching Tips: Strategies, Research, and Theory for College and University Teachers. Boston: Houghton Mifflin.

McLuhan, Marshall. 1985. "The Agenbite of Outwit." Tyuonyi 1: 58-61.

McNickle, Cathy. 2003. "The Impact that ICT Has on How We Learn-Pedagogy, Andragogy or Heutagogy?" Paper presented at the 16th Open and Distance Learning Association of Australia Biennial Forum. October 1-4, Canberra, Australia.

Nowaczyk, Ronald H., Lyndee T. Santos, and Chad Patton. 1998. "Student Perception of Multimedia in the Undergraduate Classroom." International Journal of Instructional Media 25 (4): 367-82.

Reinhardt, L. 1999. "Confessions of a Techno-Teacher." College Teaching 47 (2): 48-50.

Roberts, Matthew. 2008. "Adventures in Podcasting." PS: Political Science \& Politics 41 (3): 585-93.

Robinson, Carole F., and Peter J. Kakela. 2006. "Creating a Space to Learn: A Classroom of Fun, Interaction, and Trust." College Teaching 54 (1): 202-06.

Soper, Christopher. 2010. "Rock and Roll Will Never Die: Using Music to Engage Students in the Study of Political Science." PS: Political Science and Politics 43 (2): $363-67$.

Straits, William. 2007. “'She's Teaching $M e$ ': Teaching with Care in a Large Lecture Course." College Teaching 55 (4): 170-75.

Tufte, Edward R. 2003. The Cognitive Style of PowerPoint. Cheshire, CT: Graphics Press.

Turkle, Sherry. 2004. "How Computers Change the Way We Think." Chronicle of Higher Education, January 30, B26-B28.

Ulbig, Stacy. 2009. "Engaging the Unengaged: Using Visual Images to Enhance Students' Poli Sci 101 Experience." PS: Political Science and Politics 42 (2): 385-91.

Wilson, Karen, and James H. Korn. 2007. "Attention during Lectures: Beyond Ten Minutes.” Teaching of Psychology 34 (2): 85-89. 


\section{CAMBridge}

\section{JDURALS}

\section{Studies in}

American

STUDIES IN

AMERICAN

POLITICAL

DEVELOPMENT Political
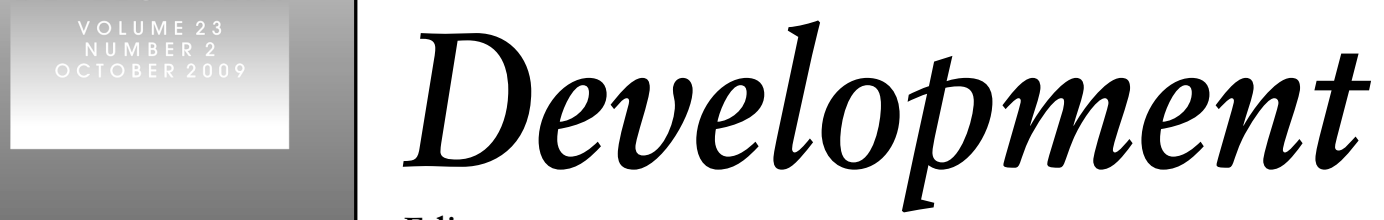

Editors:

Daniel Carpenter, Harvard University, USA

Elisabeth Clemens, University of Chicago, USA

Scott James, University of California, Los Angeles, USA

Studies in American Political Development (SAPD) publishes scholarship on political change and institutional development in the United States from a variety of theoretical viewpoints. Articles focus on governmental institutions over time and on their social, economic and cultural setting. In-depth presentation in a longer format allows contributors to elaborate on the complex patterns of state-society relations. SAPD encourages an interdisciplinary approach and recognizes the value of comparative perspectives.

\section{Studies in American Political Development Digital Archive 1986-1997}

- is a repository of every single article published in the journal between 1986 and 1997, reproduced as high-resolution, searchable PDFs

- is available as part of Cambridge Journals Digital Archive

For pricing information in the Americas: USJournals@cambridge.org

In the Rest of the World: jnlsales@cambridge.org

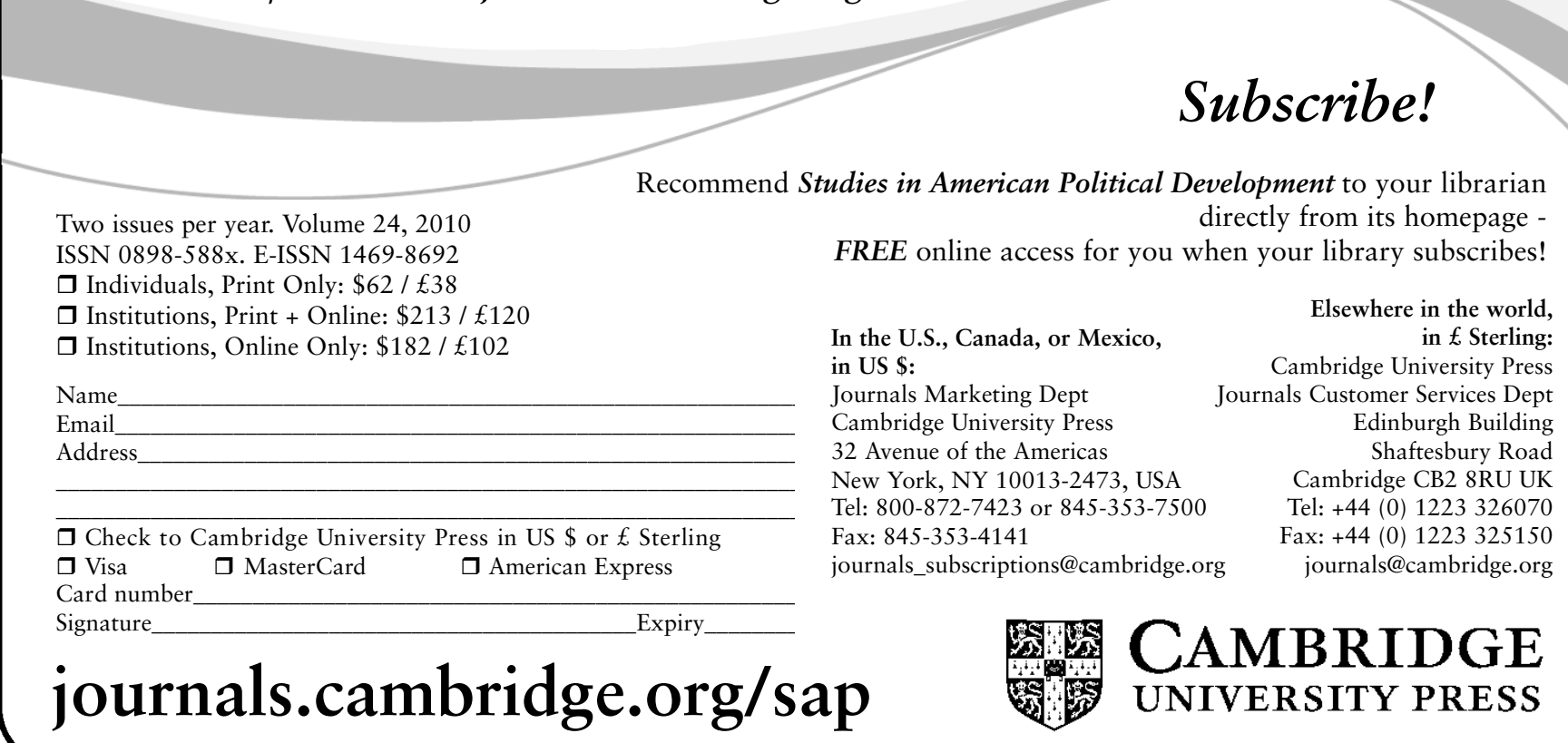

